\title{
Wound Rotor Induction Generator With Sensorless Control and Integrated Active Filter for Feeding Nonlinear Loads in a Stand-Alone Grid
}

\author{
Amit Kumar Jain, Student Member, IEEE, and V. T. Ranganathan, Senior Member, IEEE
}

\begin{abstract}
This paper describes a vector control scheme for a stand-alone generator based on a wound rotor induction machine with rotor side control. The stand-alone generator refers to an isolated grid feeding a local load. The primary objective of the control scheme is to maintain constant voltage and frequency at the output of the generator irrespective of prime mover speed variation. A novel, simple, and easily implementable sensorless control scheme is proposed. The issue of power quality, which is one of the main concerns of a stand-alone generation system, is also addressed. This is done by incorporating the active filter concept in the control scheme to cancel significant harmonics. A method of unit vector generation for field-oriented control is proposed. A laboratory prototype consisting of back-to-back insulated-gate bipolar transistor converters and a TMS320F240 DSP controller is developed. Detailed experimental results are presented which demonstrate and validate the effectiveness of the proposed scheme.
\end{abstract}

Index Terms-Active filter, doubly fed wound rotor induction machine, field oriented control, induction generator, sensorless, stand-alone generators.

\section{NOMENCLATURE}

$R_{\mathrm{S}} \quad$ Stator resistance.

$R_{\mathrm{R}} \quad$ Rotor resistance.

$L_{\mathrm{S}} \quad$ Stator inductance.

$L_{\mathrm{R}} \quad$ Rotor inductance.

$L_{\mathrm{fe}} \quad$ Input line inductance.

$R_{\mathrm{fe}} \quad$ Input line resistance.

$\alpha_{\mathrm{S}} \quad$ Stator phase winding leakage factor.

$i_{\mathrm{S} d} \quad d$-axis stator current.

$i_{\mathrm{S} q} \quad q$-axis stator current.

$i_{\mathrm{mS}} \quad$ Magnetizing current.

$i_{\mathrm{R} d} \quad d$-axis rotor current.

$i_{\mathrm{R} q} \quad q$-axis rotor current.

$i_{\text {fed }} \quad d$-axis line side converter current.

$i_{\text {fe } q} \quad q$-axis line side converter current.

$u_{\mathrm{S} d} \quad d$-axis stator voltage.

$u_{\mathrm{S} q} \quad q$-axis stator voltage.

$u_{\text {acd }} \quad d$-axis line side converter input voltage.

$u_{\text {ac } q} \quad q$-axis line side converter input voltage.

$u_{\mathrm{R} d} \quad d$-axis rotor voltage.

Manuscript received April 18, 2005; revised October 11, 2007.

The authors are with the Department of Electrical Engineering, Indian Institute of Science, Bangalore 560012, India (e-mail: amitjain@ ee.iisc.ernet.in; vtran@ee.iisc.ernet.in).

Color versions of one or more of the figures in this paper are available online at http://ieeexplore.iee.org.

Digital Object Identifier 10.1109/TIE.2007.911196

\author{
$u_{\mathrm{R} q} \quad q$-axis rotor voltage. \\ $u_{\mathrm{fe} d} \quad d$-axis line side converter reference voltage. \\ $u_{\mathrm{fe} q} \quad q$-axis line side converter reference voltage. \\ $\omega_{\mathrm{mS}} \quad$ Stator frequency. \\ $\omega_{\mathrm{S}} \quad$ Stator frequency. \\ $U_{\mathrm{S}} \quad$ Stator voltage. \\ $U_{\text {ac }} \quad$ Grid voltage. \\ $U_{\mathrm{dc}} \quad$ DC link voltage. \\ $i_{\mathrm{dc}} \quad$ DC link current. \\ $i_{\mathrm{L}} \quad$ DC link load current. \\ $i_{\mathrm{L} d} \quad d$-axis nonlinear load current. \\ $i_{\mathrm{L} q} \quad q$-axis nonlinear load current. \\ $i_{\mathrm{Ldh}} \quad d$-axis harmonic components of load current. \\ $i_{\text {Lqh }} \quad q$-axis harmonic components of load current. \\ $\varepsilon \quad$ Angle between stationary axis and rotor axis. \\ $\mu \quad$ Angle between stationary axis and stator flux axis. \\ $\theta \quad$ Angle between stationary axis and stator voltage axis.
}

\section{INTRODUCTION}

$\mathbf{T}$ HERE ARE many load centers that are isolated from the main utility grid. Some of them are remote villages, islands, ships, etc. They require isolated electric supply by means of stand-alone electrical generators to provide for their local electrical loads. This requirement has led to wide research on the development of new technologies for stand-alone generators.

The natural characteristics of nearly all prime movers used for power generators such as wind turbines, hydro turbines, diesel engines, etc., reveals that they have a tendency of speed variation depending on driving torque. Considering the prime mover characteristics, the wound rotor induction machine with field-oriented control is very attractive for high performance variable speed generation application.

In this electric generator configuration, the speed of the prime mover is allowed to vary within a certain range (subsynchronous and supersynchronous speed) and the output electrical power is always maintained at a constant voltage and constant frequency by controlling the slip power from the rotor terminals. Another fundamental feature of this configuration is that the power converters have to handle only the slip power and therefore their rating is only a fraction of the total system power.

Fig. 1 shows the block diagram of a stand-alone generating system with rotor side control. The bidirectional power flow capability is possible by the use of two back-to-back voltage 


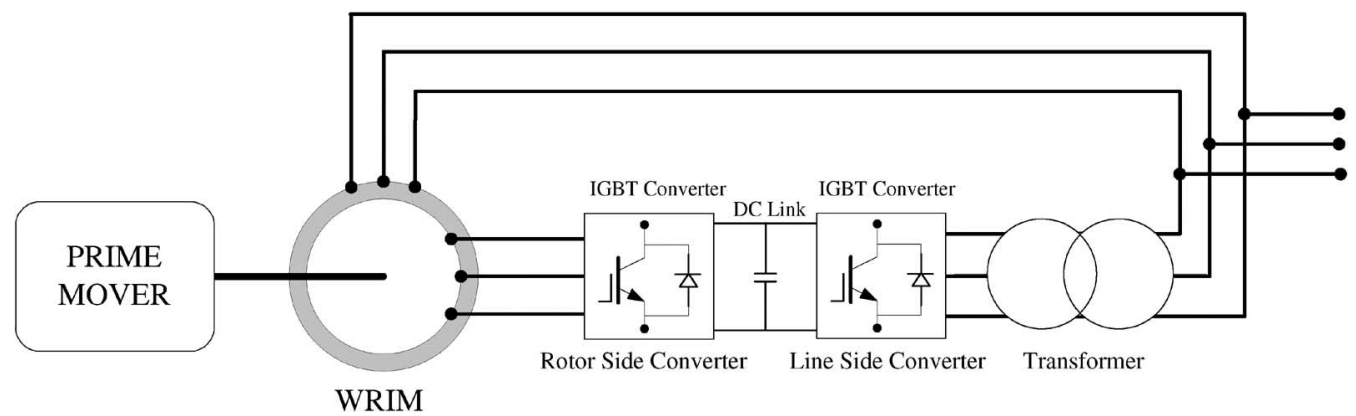

Fig. 1. Basic block diagram of stand-alone generation system with rotor side control.

source inverters with a common capacitive de link. The converters are referred to as the rotor side converter and line side converter. The line side converter is also known as the front-end converter.

The issues which need to be addressed by a stand-alone generating system are:

1) formation of a local grid and regulation of output voltage and frequency;

2) unity power factor operation of the generator;

3) operation at subsynchronous and supersynchronous speed with full torque capability;

4) sensorless operation;

5) improvement of system power quality;

6) methods of providing initial power source for machine excitation.

A lot of work has been reported on the grid connected operation of such generators. The grid connected generator technology [1]-[7] is quite mature and is in wide use today. However, very little attention has been paid toward the issues of stand-alone generators. This paper addresses the aforementioned issues of stand-alone generators.

Some experimental work has been reported for stand-alone systems [8], [9]. Most of the authors have explained the fieldoriented control strategy for the regulation of stator voltage and frequency. The stator voltage is regulated indirectly by controlling the magnetizing current of the machine, while the stator frequency is kept constant by impressing proper slip frequency currents from rotor terminals. All the schemes have used either speed or position sensor for the control. Recently, work has been reported which attempted sensorless control of a standalone doubly fed generator [9] based on the model reference adaptive system observer scheme. The effect of harmonics in the grid voltages on the control has been studied [8]; however, not much work has been reported on the compensation of harmonics.

This paper presents a control scheme which addresses nearly all the features of the stand-alone generation system mentioned above [10]. The control scheme has dedicated voltage and frequency controllers to regulate stator voltage and frequency. The control scheme proposed is novel and sensorless. It acts as a part of the frequency loop. The proposed control scheme also addresses the problem of power quality, which is one of the main concerns of stand-alone generators, by incorporating the concept of active filter operation in the control of the line side converter. The total control scheme has been tested and experimentally verified in an experimental setup. Detailed experimental results are presented to demonstrate and validate the control scheme.

Stand-alone generation systems with multiple energy sources such as wind/diesel have also been reported subsequent to this paper [11], [12]. The control methodology described here can easily find application in such systems also.

This paper is organized as follows: Details of the total experimental setup are given in Section II. Control of the rotor side converter is described in Section III. This section describes the field-oriented control strategy of voltage and frequency loops and inner current control loops. The proposed novel scheme of sensorless operation is also explained. Control of the line side converter is described in Section IV. The basic objective of the line side converter control, i.e., regulation of dc link voltage and power factor at the grid is explained. This section also presents the proposed control strategy of the active filter operation and a novel unit vector generation scheme. Section V describes the sequence in which converters are operated in the experimental setup during start up. Section VI presents the experimental results obtained from the experimental setup. Section VII concludes this paper. Appendix I gives the details of the unit vector generation scheme.

\section{DESCRIPTION OF THE EXPERIMENTAL SETUP}

The overall experimental setup for the stand-alone generator is given in Fig. 2. The power hardware circuit consists of two three-phase insulated-gate bipolar transistor (IGBT) converters with a common capacitive dc link. The converters are standard $10 \mathrm{kVA}$ pulsewidth modulation (PWM) inverters designed and fabricated in the laboratory. The line side converter is connected to stator terminals of the machine via a step-down transformer and ac series inductors. For all the experimental investigations, the dc link voltage is set at 1 $300 \mathrm{~V}$. The transformer is required to match the voltage between the dc link and stator terminals. The machine set comprises of a three-phase wound rotor induction machine coupled to a separately excited dc machine. The converter of the dc drive is operated in the torque controlled mode with a voltage limit, to guard against overspeeding on light or no load. Otherwise the speed is decided by the electrical load on the grid. The dc machine is used to emulate variable speed operation of prime movers. Details and specifications of the machine setup, converters and other power circuit elements are given in the Appendix. 


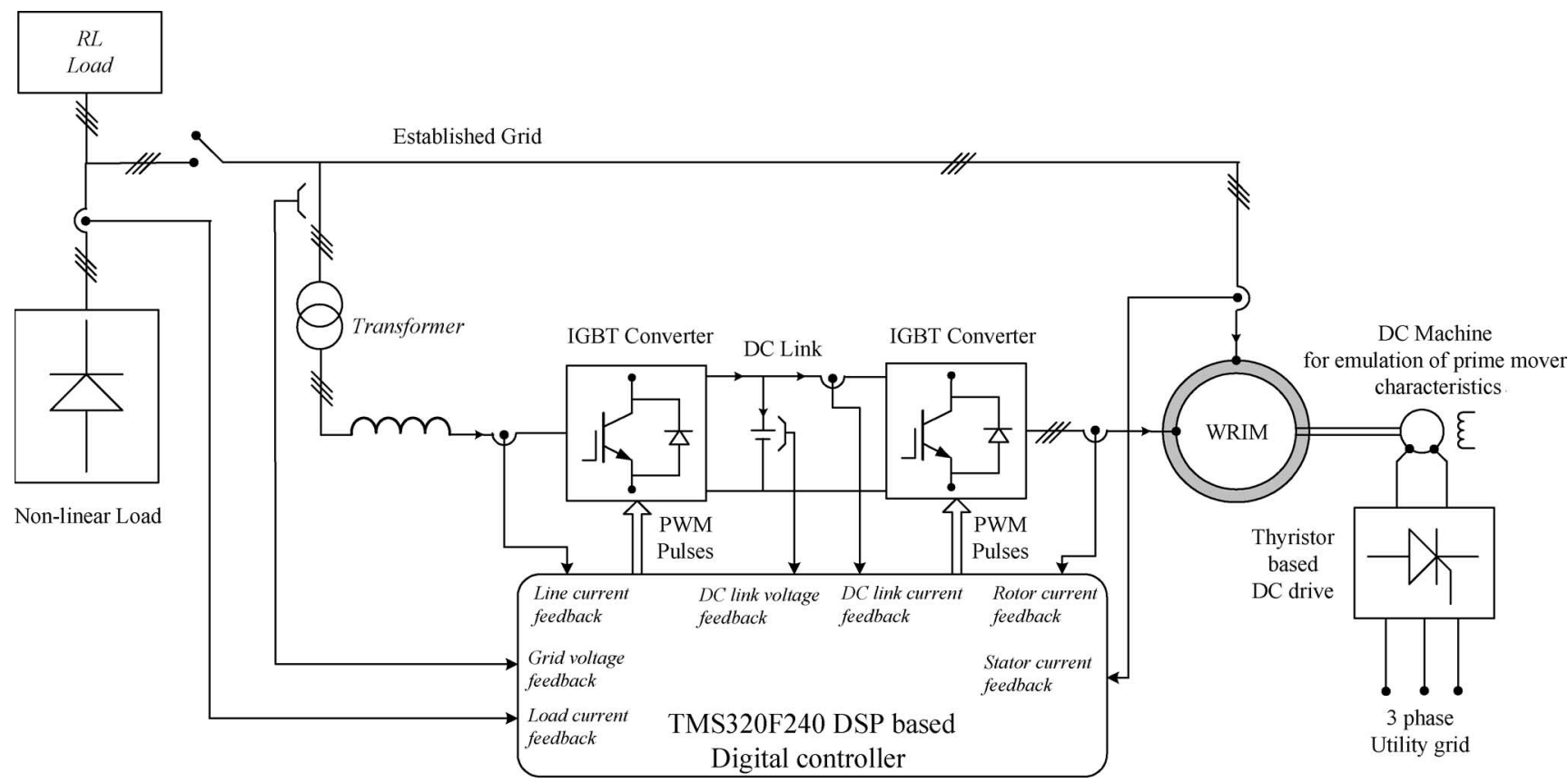

Fig. 2. Block diagram of the experimental setup.

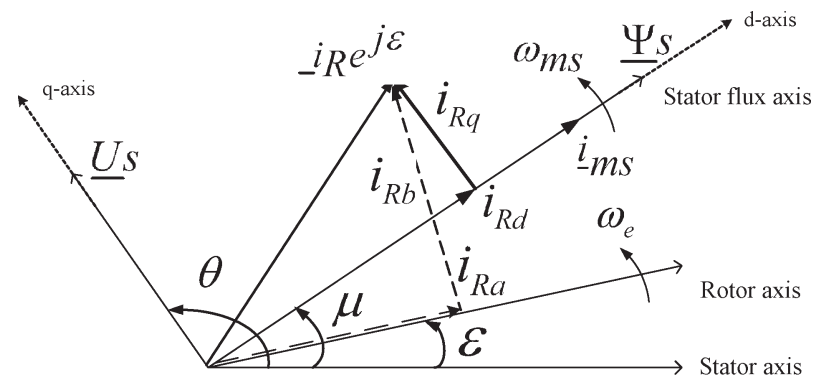

Fig. 3. Vector diagram of the field oriented control.

Two types of loads are connected at the stator terminals to emulate different types of loads at the grid. RL load is used to emulate lagging loads. To emulate nonlinear loads, a diode bridge with resistive load on the dc side is used.

For the implementation of the proposed control scheme, a TI TMS320F240 DSP-based digital controller is used. The single processor is sufficient to execute all the control algorithms of the line side converter and rotor side converter. The processor runs at a clock speed of $36 \mathrm{MHz}$. The sampling time used in this paper is $84 \mu \mathrm{s}$. The switching frequency of the line side converter and machine side converter is $2.97 \mathrm{kHz}$. All programs are written in assembly language to achieve fast, realtime control. The system is operated at a slip range of $\pm 10 \%$ around synchronous speed.

\section{Control of Rotor Side Converter}

The control of the rotor side converter for a doubly fed wound rotor induction machine using a current-controlled PWM voltage source converter has been reported widely [1]-[7]. With a controlled converter at rotor terminals, rotor currents are controlled in amplitude, frequency, and phase by applying suitable rotor voltages from the rotor side converter.

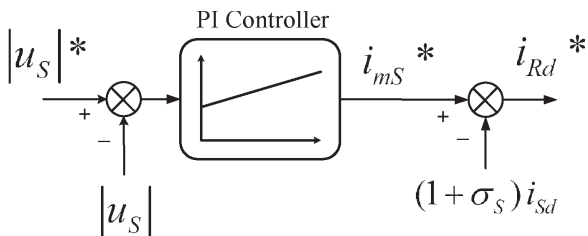

(a)

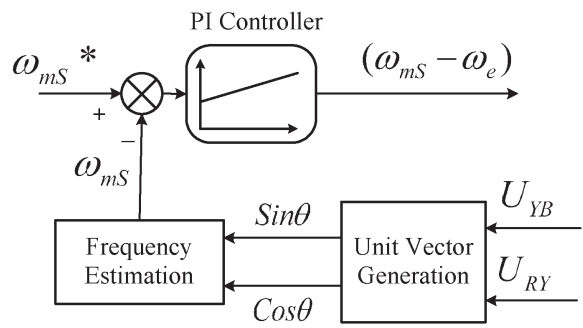

(b)

Fig. 4. Structure of voltage and frequency control loops.

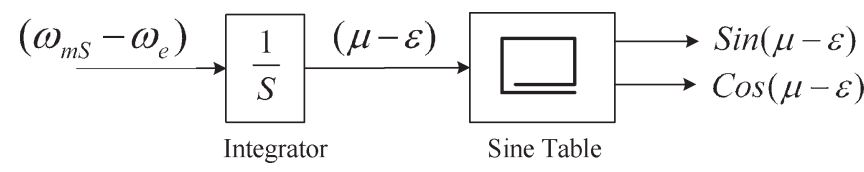

Fig. 5. Sensorless scheme of slip frequency unit vector generation.

Field-oriented control is applied to achieve fast dynamic response. The stator flux-oriented frame of reference is used for decoupling the active and reactive current control loops. The $d$-axis is aligned along the grid flux axis, while the $q$-axis is aligned along the stator voltage vector leading the $d$-axis by $90^{\circ}$ (Fig. 3). The $q$-axis current loop controls the torque of the machine by controlling the active power flow, while $d$-axis controls the flux of the machine by controlling the reactive power flow. 


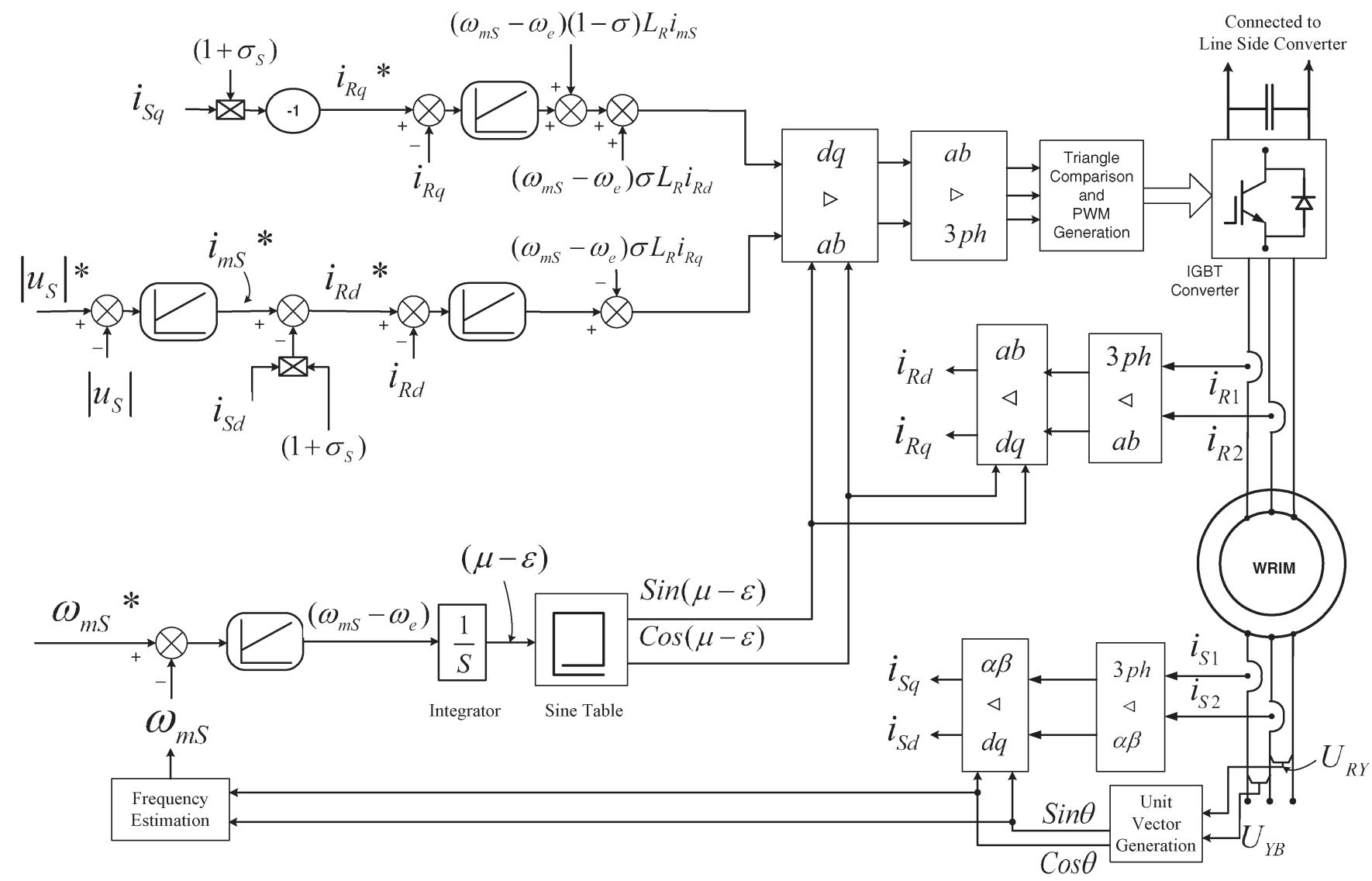

Fig. 6. Control block diagram of rotor side converter.

The dynamic equations governing the rotor currents in the stator flux coordinates [1], [4] are as follows:

$$
\begin{aligned}
\sigma T_{\mathrm{R}} \frac{d i_{\mathrm{R} d}}{d t}+i_{\mathrm{R} d}-\frac{u_{\mathrm{R} d}}{R_{\mathrm{R}}}= & \left(\omega_{\mathrm{mS}}-\omega_{\mathrm{e}}\right) \sigma T_{\mathrm{R}} i_{\mathrm{R} q} \\
& -(1-\sigma) T_{\mathrm{R}} \frac{d i_{\mathrm{mS}}}{d t} \\
\sigma T_{\mathrm{R}} \frac{d i_{\mathrm{R} q}}{d t}+i_{\mathrm{R} q}-\frac{u_{\mathrm{R} q}}{R_{\mathrm{R}}}= & -\left(\omega_{\mathrm{mS}}-\omega_{\mathrm{e}}\right) \sigma T_{\mathrm{R}} i_{\mathrm{R} d} \\
& -\left(\omega_{\mathrm{mS}}-\omega_{\mathrm{e}}\right)(1-\sigma) T_{\mathrm{R}} i_{\mathrm{mS}}
\end{aligned}
$$

where $T_{\mathrm{R}}\left(=L_{\mathrm{R}} / R_{\mathrm{R}}\right)$ is the electrical time constant of the rotor circuit and $\sigma\left(=1-\left(1 /\left(1+\sigma_{\mathrm{S}}\right)\left(1+\sigma_{\mathrm{R}}\right)\right)\right)$ is the total leakage factor of the machine. If the stator resistance drop is ignored, these can be taken as valid for grid flux also [1].

These equations are used to design the current control loops. The cross-coupling terms between the $d$-axis and $q$-axis $\left(\omega_{\mathrm{mS}}-\omega_{\mathrm{e}}\right) \sigma L_{\mathrm{R}} i_{\mathrm{R} q}$ and $\left(\omega_{\mathrm{mS}}-\omega_{\mathrm{e}}\right) \sigma L_{\mathrm{R}} i_{\mathrm{R} d}$ and disturbance input $\left(\omega_{\mathrm{mS}}-\omega_{\mathrm{e}}\right)(1-\sigma) L_{\mathrm{R}} i_{\mathrm{mS}}$ are cancelled by feedforward compensation and thereby independent control of $d$-axis and $q$-axis current loops is achieved by adding PI controllers in the loop.

For the application of stand-alone generators, the broad objectives of the rotor side converter are:

1) establishment of a local grid;

2) regulation of voltage and frequency;

$3)$ reference generation for active $(q)$ component of rotor current;

4) sensorless control.

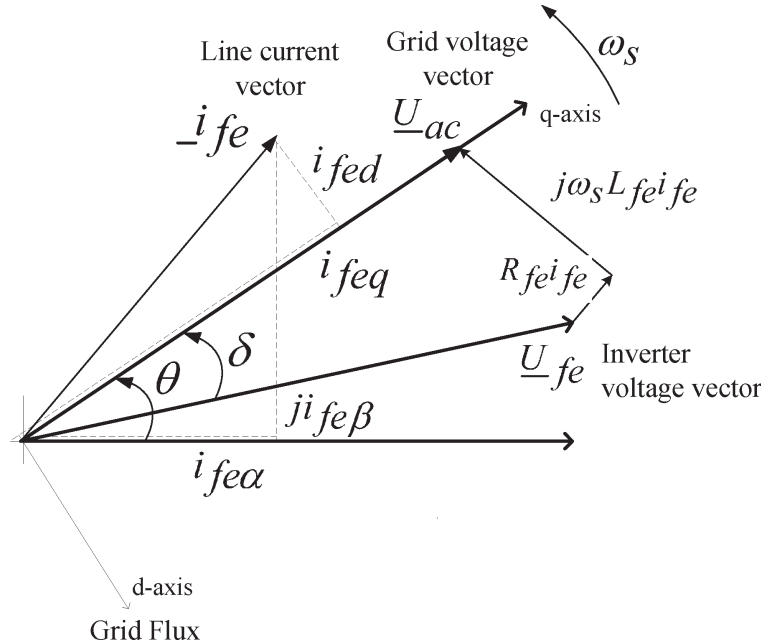

Fig. 7. Vector diagram of line side converter.

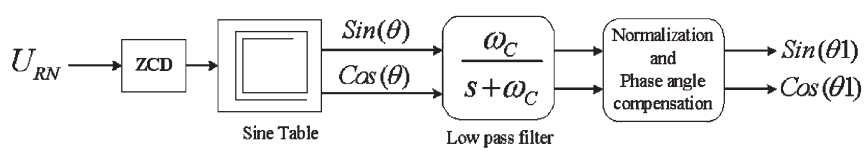

Fig. 8. Unit vector generation scheme.

To achieve the aforementioned objectives, a control strategy is proposed and will be described below. The core current loops will remain as mentioned earlier. 


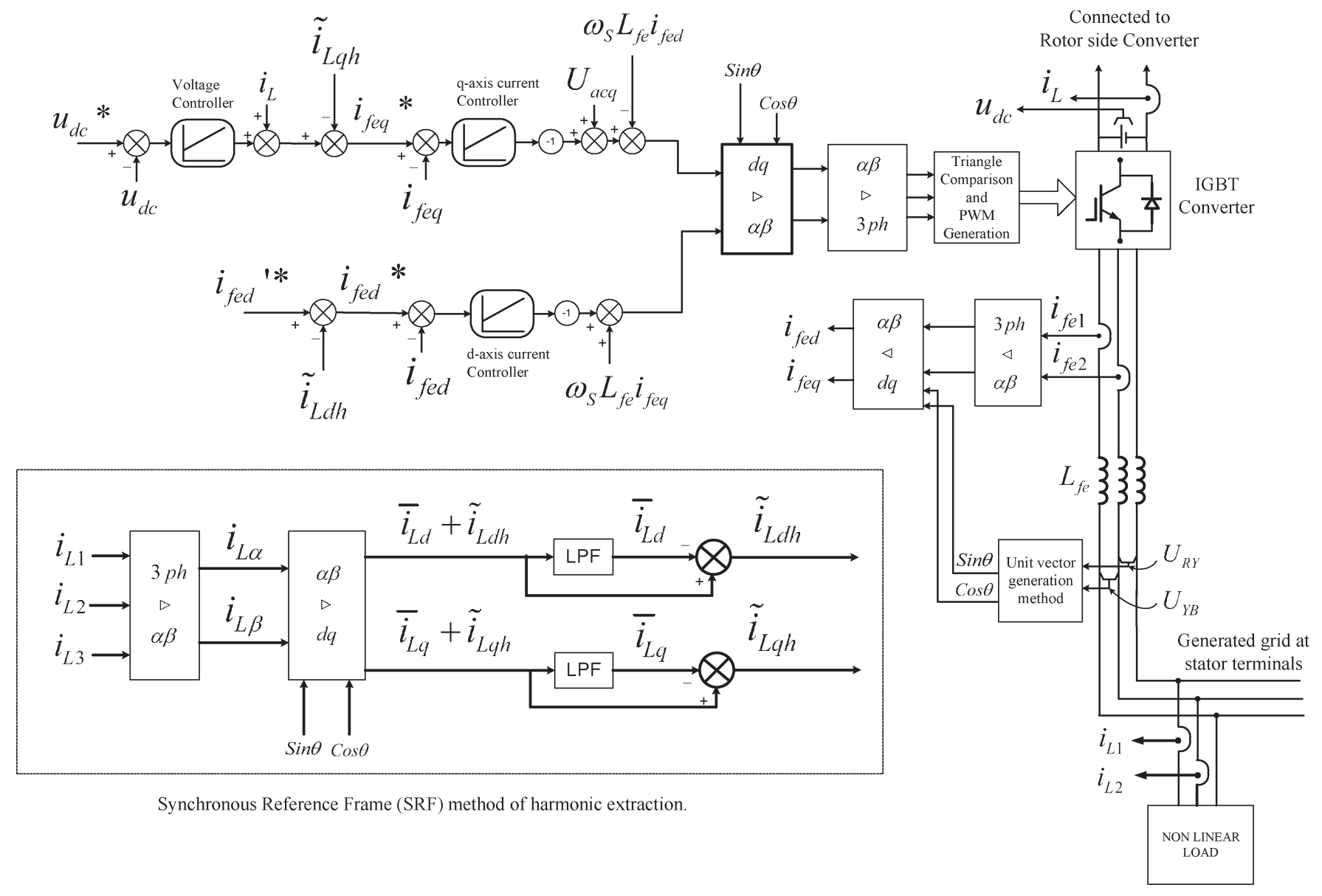

Fig. 9. Control block diagram of line side converter.

\section{A. Reference Generation for q-Axis Rotor Current Loop}

The active component $i_{\mathrm{S} q}$ of the stator current is measured; the reference for the $q$ component of the rotor current is set using

$$
i_{\mathrm{R} q}=-\left(1+\sigma_{\mathrm{S}}\right) i_{\mathrm{S} q}
$$

\section{B. Design of Voltage Loop}

The stator voltage is regulated by controlling the magnitude of the stator flux. The magnetizing current vector $\left(i_{\mathrm{mS}}\right)$ responsible for producing the stator flux is regulated to control the stator voltage magnitude. The equations governing the dynamics and steady state of the magnetizing current are

$$
\begin{aligned}
T_{\mathrm{S}} \frac{d i_{\mathrm{mS}}}{d t}+i_{\mathrm{mS}} & =\left(1+\sigma_{\mathrm{S}}\right) \frac{u_{\mathrm{S} d}}{R_{\mathrm{S}}}+i_{\mathrm{R} d} \\
i_{\mathrm{mS}} & =\left(1+\sigma_{\mathrm{S}}\right) i_{\mathrm{S} d}+i_{\mathrm{R} d} .
\end{aligned}
$$

The total magnetizing current, $i_{\mathrm{mS}}$, of the machine is supplied from the rotor side converter by $d$-axis rotor current $i_{\mathrm{Rd}}$. This is required as there is no initial grid. An external voltage loop is added such that the stator voltage is regulated by controlling the magnitude of $i_{\mathrm{mS}}$ through $d$-axis current control loop. The structure of the voltage control loop is shown in Fig. 4(a). The magnetizing current $i_{\mathrm{mS}}$ controls the magnitude of $u_{\mathrm{S} q}$ component of stator voltage which is leading it by $90^{\circ}$.
In the implementation, the stator voltage is also compensated against reactive load by feedback of $i_{\mathrm{S} d}$ as shown in Fig. 4(a). It is subtracted from the $i_{\mathrm{mS}}^{*}$ according to (5).

Alternatively, it is also possible to compensate the load reactive power through the line side converter, so that the stator operates at unity power factor.

\section{Estimation of Grid Frequency and Design of Frequency Loop}

A dedicated frequency loop is used to regulate the grid frequency. Frequency reference command is nominal grid frequency.

Actual stator frequency is estimated using the feedback of the stator line to line voltages. Initially, unit vectors are generated using a unit vector generation scheme (Appendix I). With the information of unit vectors, the actual grid frequency is estimated using the following equation:

$$
\omega_{\mathrm{mS}}=\cos (\theta) \frac{d}{d t} \sin (\theta)-\sin (\theta) \frac{d}{d t} \cos (\theta) .
$$

Because the unit vectors are generated from a stored sine table with an output low pass filter (LPF) filter, the differential terms do not contribute to any noise. However, an LPF is used (corner frequency $=100 \mathrm{~Hz}$ ) with the estimated grid frequency to suppress high-frequency noise. 


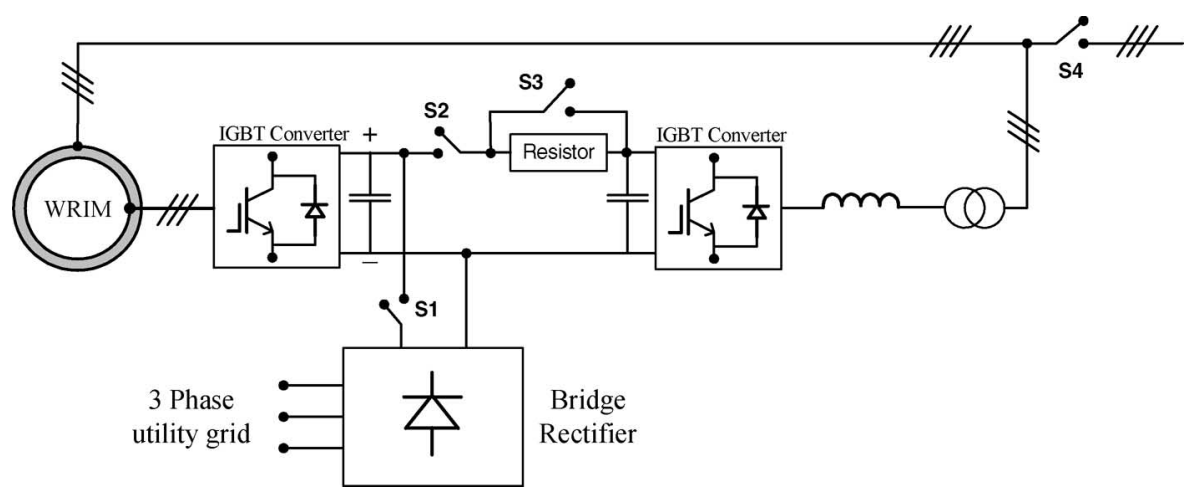

Fig. 10. Arrangement of experimental setup.

The corrective action is taken by the PI controller. The output of the controller is the slip frequency command. This is the frequency at which the rotor voltage needs to be applied from the rotor side converter to maintain constant stator frequency. The control structure is shown in Fig. 4(b).

The prime mover speed variation is sensed indirectly in this scheme. Variation in prime mover speed will reflect in variation in grid frequency for a constant rotor frequency. The difference in frequency is sensed and corrective action is taken by the controller to bring back the stator frequency to the nominal set value.

\section{Sensorless Operation}

A novel scheme of sensorless operation is proposed. It is a part of the frequency loop. With this scheme, unit vectors are generated at slip frequency $\left(\omega_{\mathrm{mS}}-\omega_{\mathrm{e}}\right)$.

Slip frequency command $\left(\omega_{\mathrm{mS}}-\omega_{\mathrm{e}}\right)$ available at the output of the frequency controller is integrated to get slip angle information $(\mu-\epsilon)$. Using the sine lookup table and slip angle information, unit vectors corresponding to slip angle and slip frequency can be generated. The unit vectors $\sin (\mu-\epsilon)$ and $\cos (\mu-\epsilon)$ are sufficient to implement the complete fieldoriented control and no separate speed or position sensors are required for the control scheme. Thus, this scheme works as a sensorless drive. The scheme is shown in Fig. 5.

\section{E. Control Block Diagram}

The complete schematic block diagram of the proposed control scheme for the rotor side converter is shown in Fig. 6.

\section{Control of Line Side Converter}

The objectives of the line side converter control in the standalone generator application are:

1) regulation of dc link voltage;

2) clean unit vector generation;

3) improved power quality of the generation system by active filter control.

The line side converter is a current controlled voltage source converter. The principle of field-oriented control is used to achieve high dynamic response. The line currents are controlled in the rotating frame of reference attached to the stator voltage

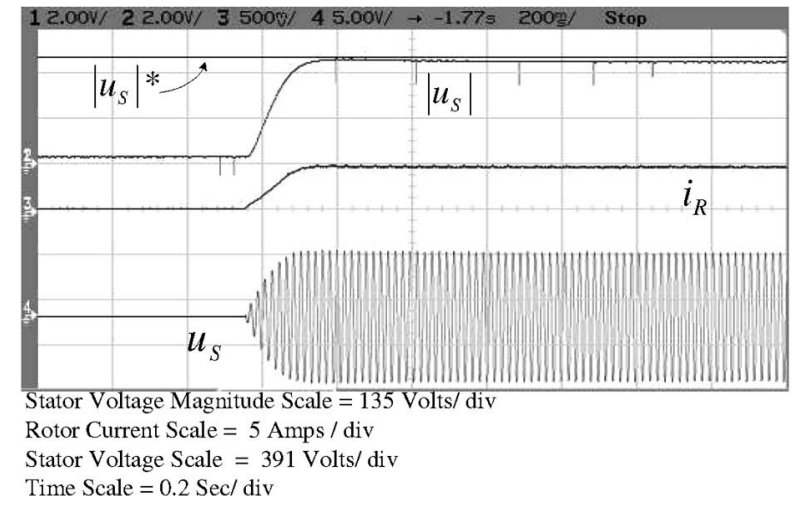

Fig. 11. Stator voltage buildup by feeding dc current from the rotor side converter (start up procedure).

vector. The $q$-axis is aligned along the stator voltage vector, while $d$-axis is lagging it by $90^{\circ}$ to maintain compatibility with the rotor side converter control (Fig. 7).

\section{A. Voltage and Current Loop}

The equations governing the dynamics of line currents in the $q$-axis and $d$-axis [1], [4] are

$$
\begin{aligned}
& T_{\mathrm{fe}} \frac{d i_{\mathrm{fe} q}}{d t}+i_{\mathrm{fe} q}=-\frac{u_{\mathrm{fe} q}}{R_{\mathrm{fe}}}+\frac{u_{\mathrm{ac} q}}{R_{\mathrm{fe}}}-\omega_{\mathrm{S}} T_{\mathrm{fe}} i_{\mathrm{fe} d} \\
& T_{\mathrm{fe}} \frac{d i_{\mathrm{fe} d}}{d t}+i_{\mathrm{fe} d}=-\frac{u_{\mathrm{fe} d}}{R_{\mathrm{fe}}}+\omega_{\mathrm{S}} T_{\mathrm{fe}} i_{\mathrm{fe} q}
\end{aligned}
$$

where $T_{\mathrm{fe}}\left(=L_{\mathrm{fe}} / R_{\mathrm{fe}}\right)$ is the time constant of line filter impedance.

These equations are used to design inner current control loops. The $d$ - and $q$-axis current loops responses are made independent by canceling the cross-coupling terms $\left(\omega_{\mathrm{S}} L_{\mathrm{fe}} i_{\mathrm{fe} d}\right.$ and $\left.\omega_{\mathrm{S}} L_{\mathrm{fe}} i_{\mathrm{fe} q}\right)$ and disturbance input $\left(u_{\mathrm{ac} q}\right)$ by introducing feedforward compensation in the loops. The control is achieved by adding a PI controller in the loops.

The equation governing the dynamics of the de link is given by the following equation:

$$
C \frac{d u_{\mathrm{dc}}}{d t}=\left(\frac{2}{3}\right)\left(\frac{u_{\mathrm{ac} q}}{u_{\mathrm{dc}}}\right) i_{\mathrm{fe} q}-i_{\mathrm{L}}
$$

In the above equation, the load current $i_{\mathrm{L}}$ acts as a disturbance input and is compensated using feedforward cancellation. The 


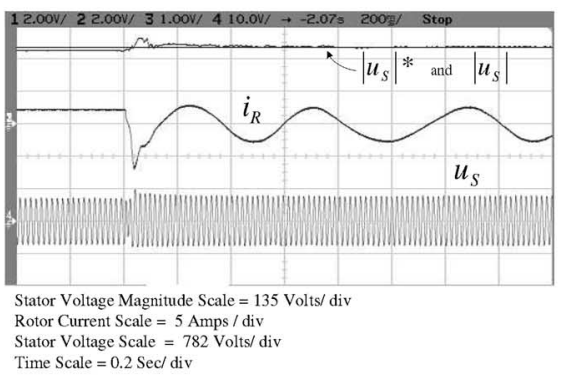

(a)

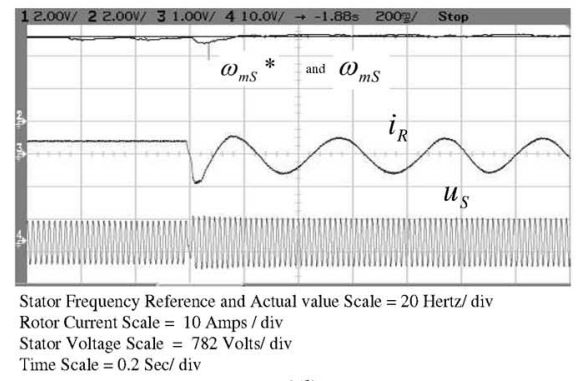

(d)

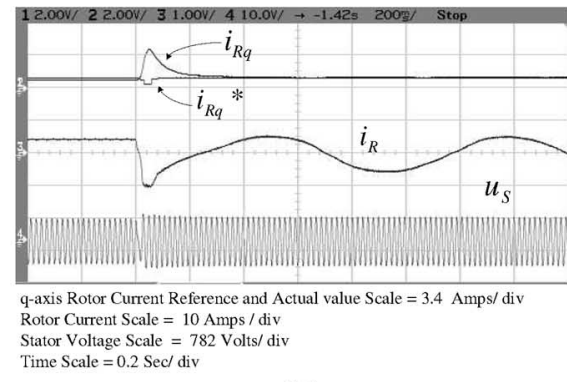

(b)

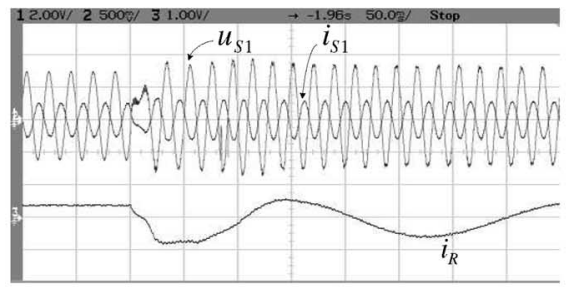

Stator Phase Voltage Scale $=102$ Volts $/$ div

Stator Current Scale $=3.4$ Amps $/ \mathrm{d}$ iv

Time Scale $=50$ milliSec/ div

(e)

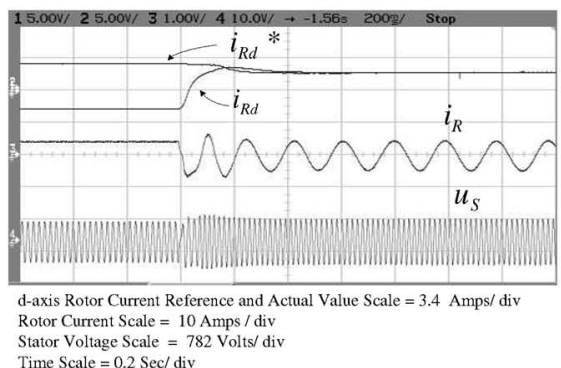

(c)

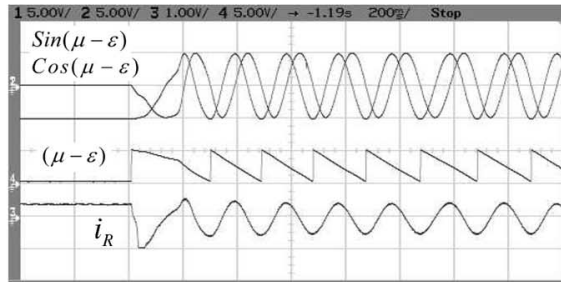

Slip angle Scale $=360$ Electrical Angle $/ \mathrm{div}$ Rotor Current Scale $=5 \mathrm{Amps} / \mathrm{div}$ Time Scale $=0.2 \mathrm{Sec} / \mathrm{div}$

(f)

Fig. 12. Responses of the different loops during transition to main control scheme. (a) Stator voltage magnitude loop response during transition. (b) $q$-axis rotor current loop response. (c) $d$-axis rotor current loop response. (d) Stator frequency loop response. (e) Stator voltage and current during transition. (f) Unit vectors and slip angle generation scheme.

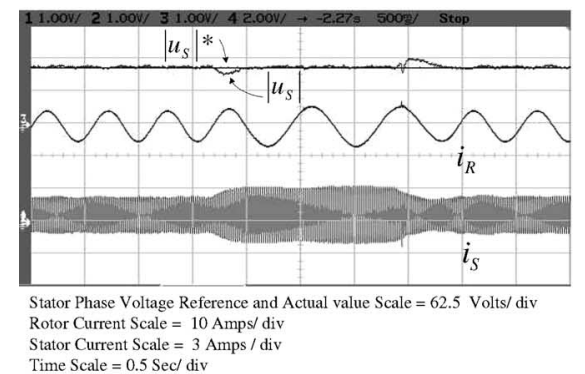

(a)

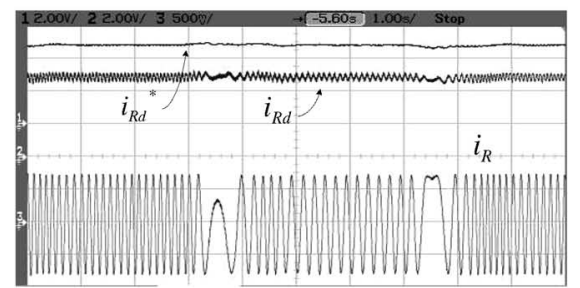

d-axis Rotor Current Reference and Actual Value Scale $=3.4$ Amps/ div Rotor Current Scale $=5$ Amps $/$ div

(d)

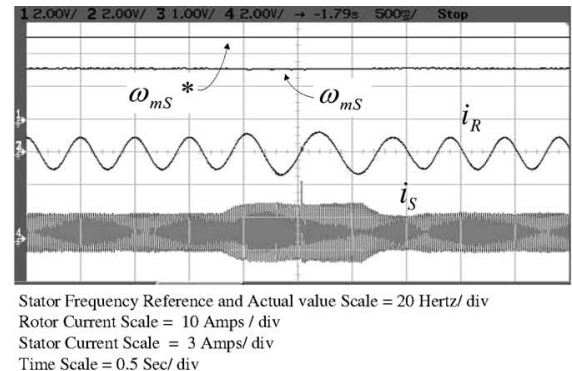

(b)

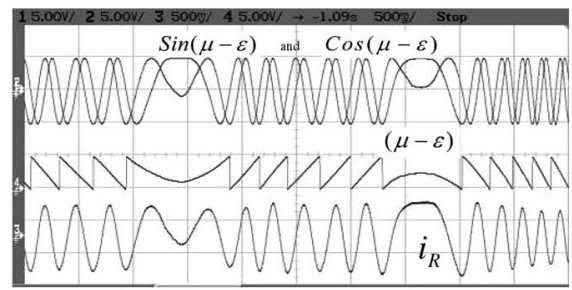

Slip angle Scale $=360$ Electrical Angle $/$ div Rotor Current Scale $=5 \mathrm{Amps} / \mathrm{div}$
Time Scale $=0.5 \mathrm{Sec} / \mathrm{div}$

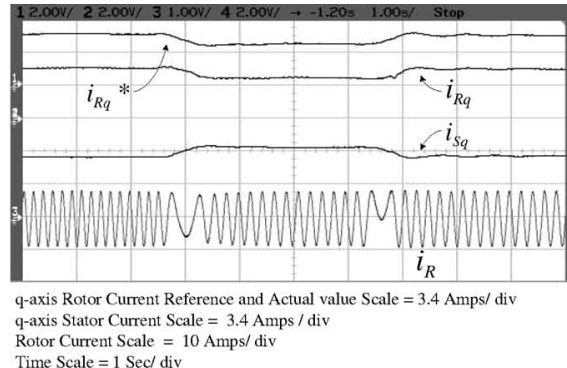

(c)

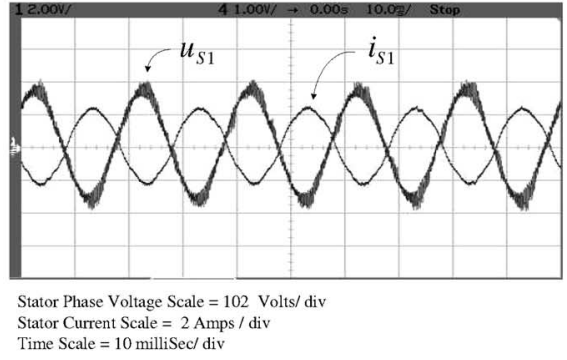

(f)

Fig. 13. Performance of the loops during step change in load and for speed variations around synchronous speed. (a) Stator voltage magnitude loop response during step change in load. (b) Stator frequency loop response during step change in load. (c) $q$-axis rotor current loop response around synchronous speed. (d) $d$-axis rotor current loop response around synchronous speed. (e) Unit vector and slip angle variation around synchronous speed. (f) Steady-state response of stator voltage and stator current.

PI voltage controller is added external to $q$-axis current loop to regulate the dc link voltage.

\section{B. Unit Vector Generation}

Unit vectors aligned to the stator voltage are required for transformations to implement field-oriented control. Generation of unit vectors from the stator voltages is sensitive to the quality of the voltage waveforms. For grid connected systems, grid voltages are rigid with less distortion. However, for standalone generators, different types of loads on the established grid affect the stator voltage waveform directly and lead to distortion frequently. Therefore, the conventional method of low-pass filter/integration of stator voltages to generate unit vectors cannot be used for stand-alone generators.

In this control scheme, a novel method is proposed which combines zero crossing detection (ZCD) method with low-pass filter for generation of unit vectors. In this scheme, only the zero 
crossings of the stator voltages are detected and no information relating to the wave-shape of the voltage is required. Using this information with sine table, unit vectors are generated at nominal grid frequency. To remove any glitches near zero crossings, these unit vectors are further integrated by a low-pass filter with further normalization and phase compensation. The cutoff frequency $\omega_{c}$ of the low-pass filter is equal to the nominal grid frequency. Fig. 8 describes the scheme of unit vector generation. A detailed scheme is explained in Appendix I.

\section{Active Filter for Improving Power Quality}

In the stand-alone generator system, maintaining the power quality of the grid is one of the main concerns. The system, by itself, acts as a local grid; therefore, nonlinear loads affect the power quality of the established grid at the stator terminals directly.

To address this issue and to compensate for the undesirable harmonics drawn by nonlinear loads, a control scheme is proposed. In this scheme, the concept of shunt active filter is incorporated with the line side converter control.

The shunt active filter [13]-[16] is based on the principle of injection of load harmonic current from the line side converter. In the present scheme, synchronous reference frame (SRF) method is used for extraction of harmonic components from nonlinear load currents. The SRF scheme is described in Fig. 9. In this scheme, load currents are measured and harmonics components are extracted in $d-q$ frame attached to the stator voltages. In synchronous $d-q$ frame, the fundamental positive sequence components are $\mathrm{dc}$ and all harmonic components are ac. A high-pass filter realization is used to extract ac harmonic components. The corner frequency of the low-pass filter is $2 \mathrm{~Hz}$.

The extracted $q$-axis and $d$-axis harmonic of load components $\left(i_{\mathrm{Ldh}}\right.$ and $\left.i_{\mathrm{Lqh}}\right)$ are subtracted from the actual $q$-axis and $d$-axis line current references $\left(i_{\mathrm{fe} d}^{*}\right.$ and $i_{\mathrm{fe} q}^{*}$ ) of the line side converter control. Now, the harmonic current demanded by the load is supplied by the line side converter rather than the stator current. Therefore, the stator current and stator voltage will have good sinusoidal wave-shape with low harmonic content.

\section{Control Block Diagram of Line Side Converter}

The complete schematic control block diagram of the line side converter is shown in Fig. 9.

\section{Experimental Setup-Operational SEQuence}

A simple experimental setup is used to demonstrate and validate the control scheme. This is shown in Fig. 10. Stand-alone generators require an external power source for excitation of the machine during start up. In the experimental setup, switches S1, $\mathrm{S} 2$, and S3 will be initially open. The dc bus for the rotor side converter is then charged by an arrangement of uncontrolled rectifier and utility three-phase grid supply (by closing switch S1). First, the rotor side converter control is released with a soft start-up procedure and a local grid is formed at the stator terminals. It is followed by the release of the line side converter control with the available grid to create a regulated dc at the output of the line side converter. This dc voltage itself

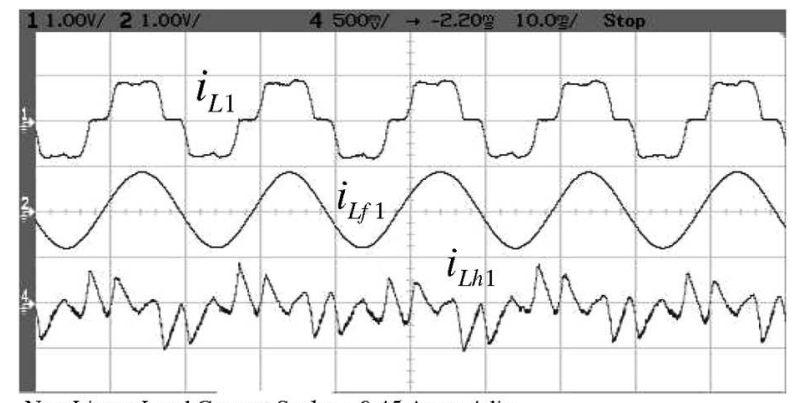

Non Linear Load Current Scale $=0.45 \mathrm{Amps} / \mathrm{div}$

Fundamental Component of Load Current Scale $=0.45 \mathrm{Amps} / \mathrm{div}$

Harmonic Component of Load Current Scale $=0.9 \mathrm{Amps} / \mathrm{div}$

Time Scale $=10$ milliSec/ div

(a)

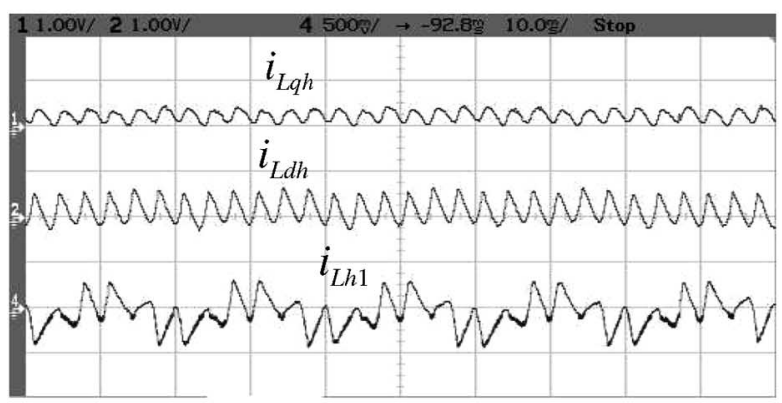

d-axis harmonic Component of Load Current Scale $=1.35 \mathrm{Amps} / \mathrm{div}$ q-axis harmonic Component of Load Current Scale $=1.35 \mathrm{Amps} / \mathrm{div}$

Harmonic Component of Load Current Scale $=0.45 \mathrm{Amps} / \mathrm{div}$

Time Scale $=10$ milliSec/ div

(b)

Fig. 14. Extraction of harmonic components of load current by SRF method. (a) Fundamental and harmonic components of load current. (b) Harmonic component of load current in $q$-axis and $d$-axis.

is then used to drive the rotor side converter (switch S2 is closed first and then switch S3 is closed after some time). The bridge rectifier arrangement is then removed form the setup (by opening the switch S1). Afterward, the system operates on its own in stand-alone mode (now the switch S4 is closed).

\section{EXPERIMENTAL Results}

Experimental results demonstrating the transient and steadystate performance of the control scheme for the rotor side converter and line side converter are presented in this section.

\section{A. Rotor Side Converter Control-Start-Up Procedure}

A soft start-up procedure is followed to build up the stator voltage in a smooth manner and to avoid undesirable transients. Initially, a constant dc voltage is applied from the rotor terminals using the rotor side converter. With the prime mover in rotation, the induction machine will act as a synchronous generator. Voltages are established at stator terminals whose magnitude and frequency is proportional to the rotor speed.

After a delay the actual control scheme is released for the rotor side converter. With the measurement of stator voltage and frequency the initial error is known. This enables suitable corrective action by means of voltage and frequency controllers and thus avoids any transients at start up. 


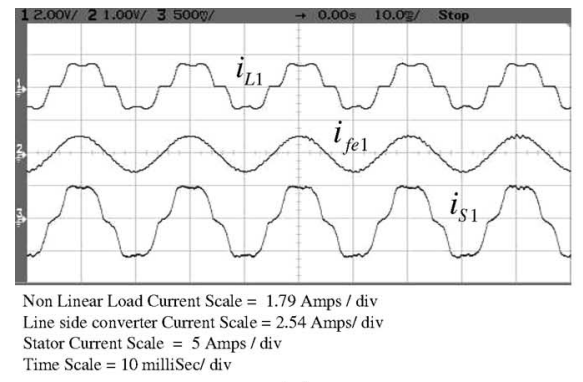

(a)

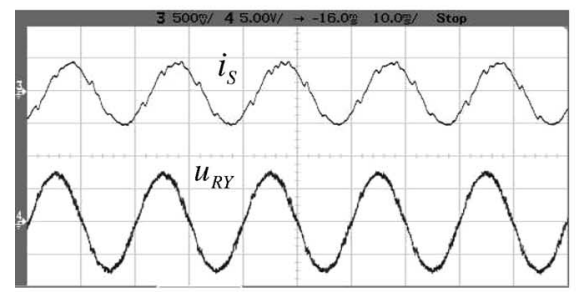

Stator Phase Current Scale $=5 \mathrm{Amps} / \mathrm{div}$ Stator Line to Line Voltage Scale $=391$ Volts $/$ div Time Scale $=10$ milliSec/ div

(d)

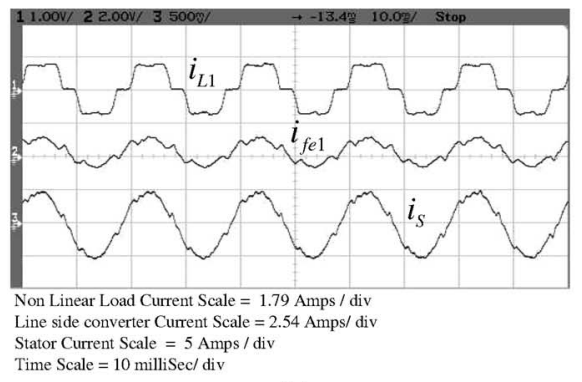

(b)

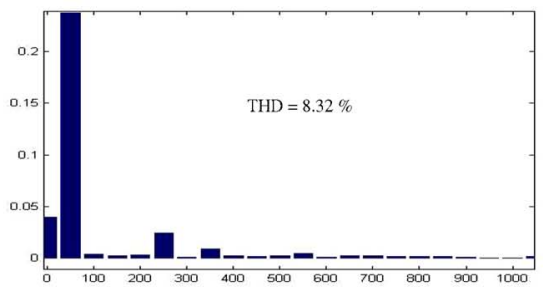

(e)

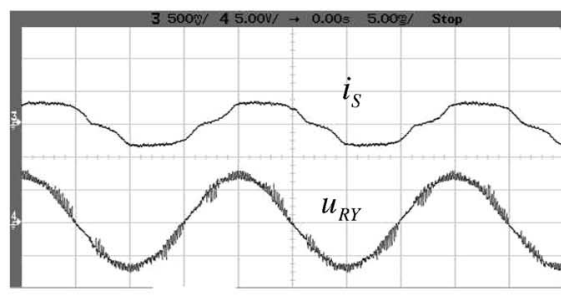

Stator Phase Current Scale $=5 \mathrm{Amps} / \mathrm{div}$ Stator Line to Line Voltage Scale $=391$ Volts $/$ div Time Scale $=5$ milliSec/ div

(c)

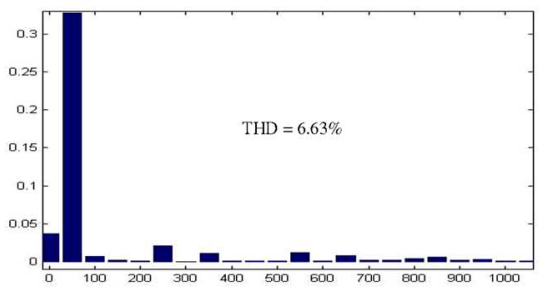

(f)

Fig. 15. Compensation of harmonics components of load current using active filter control and THD measurement. (a) Line current and stator current without compensation. (b) Line current and stator current with compensation. (c) Stator voltage and stator current without compensation. (d) Stator voltage and stator current with compensation. (e) FFT of stator current without compensation. (f) FFT of stator current with compensation.

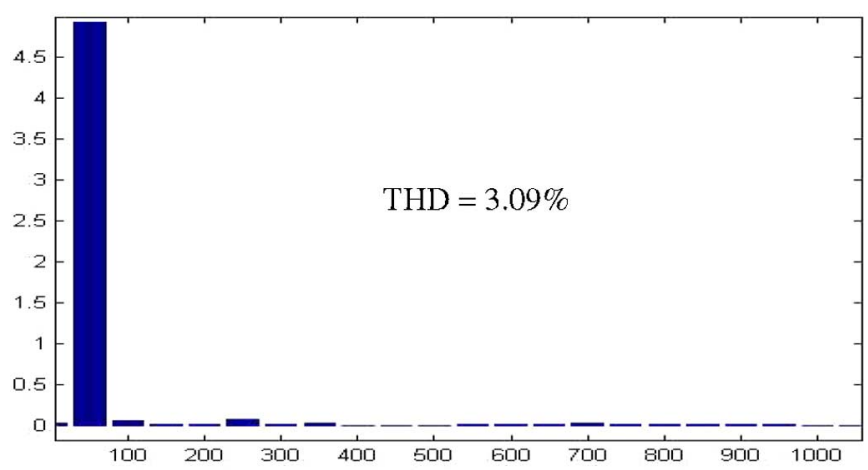

(a)

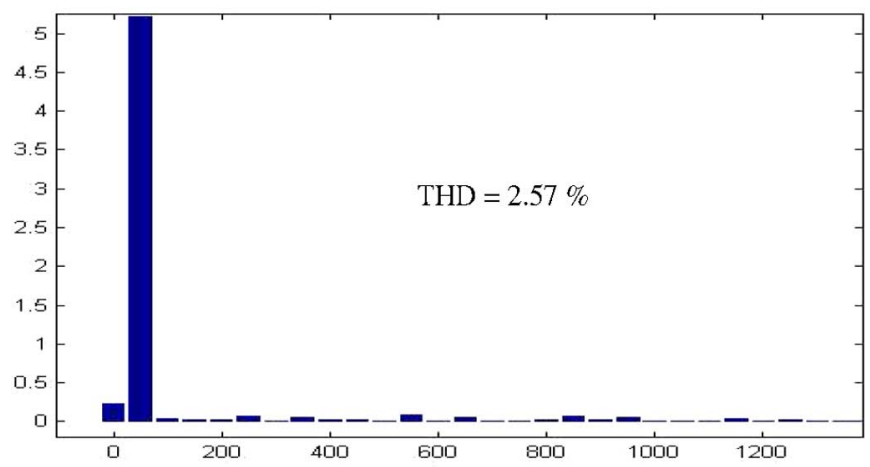

(b)

Fig. 16. Performance analysis of the active filter operation using THD measurement. (a) FFT of stator voltage without compensation. (b) FFT of stator voltage with compensation.

Fig. 11 shows the smooth build up of the voltage at the stator when a constant dc rotor current is applied from the rotor terminals.

\section{B. Rotor Side Converter Control-Performance of Different Loops During Transition to Main Control}

The response of the different loops during changeover to the main control scheme after the start-up process are shown in Fig. 12(a)-(f). The response of the stator voltage magnitude loop is shown in Fig. 12(a). The response of the $q$-axis current loop, $d$-axis current loop, and frequency loop are shown in Fig. 12(b)-(d), respectively. All these figures also show the stator voltage and rotor current.

Fig. 12(e) shows the stator voltage and stator current during transition to actual control. It can be observed that there is no voltage or current spike. Fig. 12(f) shows the unit vector generation and slip angle of the sensorless scheme.

Fig. 12(a)-(f) show results pertaining to transition from dc excitation to the control of the frequency. The shaft speed during transition is $1550 \mathrm{r} / \mathrm{min}$. During these experiments, the electrical load on the grid is negligible apart from the magnetizing current of the transformer connected to the line side converter. Rotor current is dominantly reactive required for magnetizing the induction machine.

\section{Rotor Side Converter Control-Performance During Step Change in Load at the Grid}

The response of the voltage magnitude and frequency loop during step change of the load at the grid is shown in Fig. 13(a) and (b). The variation of load change is from $25 \%$ to $50 \%$ of the motor rated torque and vice versa. The nature of the load is predominantly $\mathrm{R}$ with very little inductance. In the case of RL load, the reactive power drawn from the stator (proportional to $i_{\mathrm{S} d}$ ) is compensated with adjustment in $i_{\mathrm{R} d}$ to keep grid voltage constant (Fig. 6). 


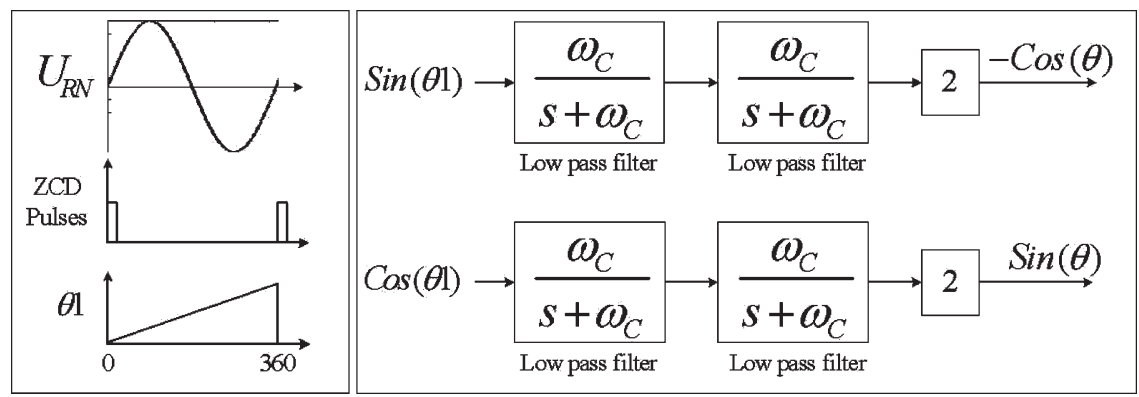

Fig. 17. Generation of unit vectors from ZCD method.

\section{Rotor Side Converter Control-Performance Around the Synchronous Speed and Steady State Response}

The transient performance of the loops for variation of the prime mover speed from subsynchronous speed to supersynchronous speed and vice versa is shown in Fig. 13(c)-(e). It can be noticed that transient performance is smooth. The stator voltage and stator current at steady state are shown in Fig. 13(f).

The variation of speed change is from around $1350 \mathrm{r} / \mathrm{min}$ to around $1650 \mathrm{r} / \mathrm{min}$ (i.e., close to $\pm 10 \%$ variation). This is confirmed from the rotor current frequency which has a variation of around $\pm 5 \mathrm{~Hz}$. The speed is changed by varying the voltage limits of the controlled drive for the dc machine.

\section{E. Line Side Converter Control-Extraction of Harmonic Component of Load Current}

The harmonic components are extracted using the SRF scheme. Fig. 14(a) shows the measured load current $i_{\mathrm{L} 1}$ with its fundamental component $\left(i_{\mathrm{Lf} 1}\right)$ and harmonic component $\left(i_{\mathrm{Lh} 1}\right)$. The harmonic current components $i_{\mathrm{Lqh}}$ and $i_{\mathrm{Ldh}}$ extracted by filtering in the synchronous frame of reference are shown in Fig. 14(b). The nonlinear load is a rectifier feeding a predominantly $\mathrm{R}$ load with low inductance value.

\section{F. Line Side Converter Control-Active Filter Compensation of Harmonic Load Current}

Fig. 15(a) shows the waveform of the stator current and line side converter current without active filter compensation. The line side converter current is sinusoidal without active filter action. It can be observed that the stator current waveform is distorted as it has to supply the harmonic components of the load.

Fig. 15(b) shows the stator current and line side converter current with active filter action incorporated in line side converter control. Now, the line side converter supplies the harmonic component of the load current and therefore the stator current is nearly sinusoidal with lower harmonic content.

Fig. 15(c) and (d) shows the waveform of the stator line to line voltage and stator current without compensation and with compensation, respectively. As the waveform shows line to line voltage $U_{\mathrm{RY}}$ rather than $U_{\mathrm{RN}}$ ( $U_{\mathrm{RY}}$ leads the $U_{\mathrm{RN}}$ by $30^{\circ}$ ), the voltage is leading the current $i_{\mathrm{S} 1}$ by $30^{\circ}$. The actual phase to neutral voltage $U_{\mathrm{RN}}$ is nearly in unity power factor to current $i_{\mathrm{S} 1}$ as the load is dominantly $\mathrm{R}$ load [similar to Fig. 13(f)].

\section{G. Line Side Converter Control-Performance Analysis Through Total Harmonic Distortion (THD) Measurement}

Performance improvement is measured using THD calculation. The Fast Fourier Transforms (FFT) of the stator current and stator voltage without and with compensation is shown in Figs. 15(e) and (f) and 16(a) and (b), respectively. The THD of the stator current is improved from $8.32 \%$ to $6.63 \%$, while the THD of the stator voltage is improved from $3.05 \%$ to $2.57 \%$.

\section{CONCLUSION}

A vector control scheme for stand-alone generators based on a wound rotor induction machine with rotor side control has been developed. The objectives of the stand-alone generator such as establishment of a local grid and regulation of its voltage and frequency are achieved using a novel and simple sensorless scheme. The active filter concept is added in the control scheme of the line side converter to improve power quality. Detailed experimental results are presented which validate and demonstrate the performance and features of the control scheme.

\section{APPENDIX I}

\section{Details of Unit Vector Generation Scheme}

In this scheme, the unit vectors required for transformations and estimation of grid frequency are generated using feedback of line to line voltages $U_{\mathrm{RY}}$ and $U_{\mathrm{YB}}$.

Initially, R-phase to neutral voltage is calculated using $U_{\mathrm{RY}}$ and $U_{\mathrm{YB}}$ as

$$
U_{\mathrm{RN}}=\frac{1}{3}\left(2 U_{\mathrm{RY}}+U_{\mathrm{YB}}\right)
$$

The positive zero crossing of $U_{\mathrm{RN}}$ is sensed for generation of angle variation information $\theta 1$ from $0^{\circ}$ to $360^{\circ}$ [Fig. 17]. Since there is a frequency control loop, the stator frequency is always controlled to be at nominal grid frequency, i.e., $50 \mathrm{~Hz}$. This is taken advantage of in generating the angle $\theta 1$. Using the stored sine table, the $\theta 1$ information is converted to sine and cosine unit vectors, such that $\cos (\theta 1)$ is in phase with $U_{\mathrm{RN}}$ and $\sin (\theta 1)$ is lagging $-90^{\circ}$ to $U_{\mathrm{RN}}$. There may be a few glitches in the unit vectors near the zero crossing due to noise in the signal and due to small frequency variations. To eliminate these glitches, an LPF is used. The inclusion of a low-pass filter creates attenuation and phase shift but these are suitably compensated. 
In this scheme, two low-pass filters are used whose corner frequency is equal to the nominal grid frequency. The attenuation and phase shift generated from each LPF is $1 / \sqrt{2}$ and $-45^{\circ}$, respectively. Thus, the total attenuation and phase shift due to two LPFs will be $1 / 2$ and $-90^{\circ}$, respectively. The attenuation is compensated by introducing a gain of 2 . The $-90^{\circ}$ phase lag is taken care of by using outputs as $-\cos (\theta)$ and $\sin (\theta)$ as shown in Fig. 17.

\section{APPENDIX II \\ EXPERIMENTAL SETUP}

WRIM Specification

$3 \mathrm{KW}, 415 \mathrm{~V}, 50 \mathrm{~Hz}, 4$ pole, 3 phase, NGEF make

STATOR : $415 \mathrm{~V}, \Delta$ connected, $7.2 \mathrm{~A}$.

ROTOR : $415 \mathrm{~V}, \mathrm{Y}$ connected, $6.6 \mathrm{~A}$.

$R_{\mathrm{S}}=1.557 \mathrm{ohms}, R_{\mathrm{R}}=2.62 \mathrm{ohms}$,

$L_{\mathrm{S}}=L_{\mathrm{R}}=195 \mathrm{mH}$ and $L_{\mathrm{O}}=177 \mathrm{mH}$.

Power Converters

$1200 \mathrm{~V}, 50$ A SEMIKRON IGBT (SKM12350GB).

DC link Capacitor $=2000 \mu \mathrm{F}$.

Transformer

$2 \mathrm{kVA}, 3$ phase, $50 \mathrm{~Hz}, 415 \mathrm{~V} / 125 \mathrm{~V}$.

AC Side Inductor

Inductor value $=17 \mathrm{mH}$.

DC Machine

5.6 KW, 1500 r/min, Separately Excited Machine.

\section{REFERENCES}

[1] W. Leonhard, Control of Electrical Drives, 3rd ed. Berlin, Germany: Springer-Verlag, 2003.

[2] L. Xu and W. Cheng, "Torque and reactive power control of a doubly fed induction machine by position sensorless scheme," IEEE Trans. Ind. Electron., vol. 31, no. 3, pp. 636-642, May/Jun. 1995.

[3] R. Pena, J. C. Clare, and G. M. Asher, "Doubly fed induction generator using back-to-back PWM converters and its application to variable-speed wind-energy generation," Proc. Inst. Electr. Eng.-Electrical Power Applications, vol. 143, no. 3, pp. 231-241, May 1996.

[4] R. Datta and V. T. Ranganathan, "A simple position-sensorless algorithm for rotor-side field-oriented control of wound-rotor induction machine," IEEE Trans. Ind. Electron., vol. 48, no. 4, pp. 786-793, Aug. 2001.

[5] G. Poddar and V. T. Ranganathan, "Sensorless double-inverter-fed woundrotor induction-machine drive," IEEE Trans. Ind. Electron., vol. 53, no. 1, pp. 86-95, Feb. 2006.

[6] J. M. Carrasco, L. G. Franquelo, J. T. Bialasiewicz, E. Galvan, R. C. Portillo Guisado, M. A. M. Prats, J. I. Leon, and N. Moreno-Alfonso, "Power-electronic systems for the grid integration of renewable energy sources: A survey," IEEE Trans. Ind. Electron., vol. 53, no. 4, pp. 10021016, Jun. 2006

[7] M. T. Abolhassani, P. Enjeti, and H. A. Toliyat, "Integrated doubly-fed electric alternator/active filter (IDEA), a viable power quality solution, for wind energy conversion systems," in Conf. Rec. IAS Annu. Meeting, Oct. 2004, vol. 3, pp. 2036-2043. no. 5 .
[8] R. Pena, J. C. Clare, and G. M. Asher, "A doubly fed induction generator using back-to-back PWM converters supplying an isolated load from a variable speed wind turbine," Proc. Inst. Electr. Eng.-Electrical Power Applications, vol. 143, no. 5, pp. 380-387, Sep. 1996.

[9] R. Pena, R. Cardenas, J. Proboste, J. C. Clare, and G. M. Asher, "Sensorless control of a doubly-fed induction generator for stand alone operation," in Proc. IEEE Power Electron. Spec. Conf., Jun. 2004, vol. 5, pp. 3378-3383.

[10] A. K. Jain, "Control of stand-alone variable speed generation system using wound rotor induction machine," M.S. (Engg.) thesis, Dept. Elect. Eng., IISc Bangalore, Bangalore, India, Dec. 2004.

[11] R. Pena, R. Cardenas, J. Proboste, J. Clare, and G. Asher, "A hybrid topology for a variable speed wind-diesel generation system using wound rotor induction machines," in Proc. IEEE IECON Conf., Nov. 2005, pp. 2457-2462.

[12] R. Cardenas, R. Pena, M. Perez, J. Clare, G. Asher, and F. Vargas, "Vector control of front-end converters for variable-speed wind-diesel systems," IEEE Trans. Ind. Electron., vol. 53, no. 4, pp. 1127-1136, Jun. 2006.

[13] H. Akagi, "Trends in active power line conditioners," IEEE Trans. Power Electron., vol. 9, no. 3, pp. 263-268, May 1994.

[14] S. Buso, L. Malesani, and P. Mattavelli, "Comparison of current control techniques for active filter applications," IEEE Trans. Ind. Electron., vol. 45, no. 5, pp. 722-729, Oct. 1998.

[15] S. Bhattacharya, T. M. Frank, D. M. Divan, and B. Banerjee, "Active filter system implementation," IEEE Ind. Appl. Mag., vol. 4, no. 5, pp. 47-63, Sep./Oct. 1998.

[16] S. Senini and P. J. Wolfs, "Analysis and design of a multiple-loop control system for a hybrid active filter," IEEE Trans. Ind. Electron., vol. 49, no. 6, pp. 1283-1292, Dec. 2002.

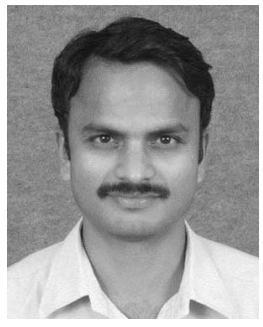

Amit Kumar Jain (S'04) was born in Bhilai, India, in 1975. He received the B.E. degree in electrical engineering from Shri Govindram Sakseria Institute of Technology and Science, Indore, India, in 1999, and the M.Sc. (Engg.) degree in electrical engineering from the Indian Institute of Science (I.I.Sc.), Bangalore, India, in 2004, where he is currently working toward the Ph.D. degree in the Department of Electrical Engineering.

Following the receipt of the B.E. degree, he spent two and half years, at the Department of Electrical Engineering, I.I.Sc., as a Project Staff member. During this period he was involved with various research and development projects sponsored by leading companies such as, BARC, BEL and Lucas-TVS Pvt, Ltd. His research interests are in the area of induction machine drives, synchronous machine drives, active filters, and converter design.

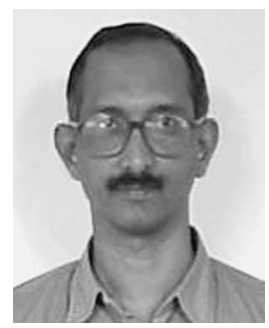

V. T. Ranganathan (M'86-SM'95) was born in Chennai, India, in 1955. He received the B.E. and M.E. degrees in electrical engineering from the Indian Institute of Science (I.I.Sc.), Bangalore, India, in 1977 and 1979, respectively, and the Ph.D. degree from Concordia University, Montreal, QC, Canada, in 1984.

He joined the Electrical Engineering Department at I.I.Sc., in 1984, as an Assistant Professor and is currently a Professor. His research interests are in the area of power electronics and motor drives. He has made significant research contributions in the areas of vector control of ac drives, pulsewidth-modulation techniques, split-phase induction motor drives, and slip ring induction motor drives. His work has led to a number of publications in leading journals, as well as patents. He is also active as a consultant to industry and has participated in a number of research and development projects in various areas, such as industrial drives, servodrives, traction drives, wind energy, and automotive applications.

Prof. Ranganathan was the recipient of a Prize Paper Award from the Static Power Converter Committee of the IEEE Industry Applications Society in 1982, the Tata Rao Prize of the Institution of Engineers India from 1991 to 1992, the VASVIK Award in Electrical Sciences and Technology in 1994, and the Bimal Bose Award of the Institution of Electronics and Telecommunication Engineers, India in 2001. He is a Fellow of the Indian National Academy of Engineering and the Institution of Engineers, India. 